\title{
New Technique for Aortic Valve Functional Annulus Reshaping Using a Handmade Prosthetic Ring
}

\author{
Khalil Fattouch, MD, PhD, Roberta Sampognaro, MD, Giuseppe Speziale, MD, and \\ Giovanni Ruvolo, MD \\ Department of Cardiac Surgery, University of Palermo, Palermo, and GVM Care and Research, Palermo and Bari, Italy
}

Background. Despite a wide development in aortic leaflets repair techniques, aortic valve annuloplastic procedures are still poorly investigated. We present our aortic valve annuloplastic system consisting of a handmade prosthetic ring with 2 components for reshaping the aortic annulus and sinotubular junction (STJ) and illustrates our surgical approach and clinical results.

Methods. Since February 2003, 45 patients with aortic valve regurgitation underwent aortic annuloplasty using the new ring. Mean patient age was $58 \pm 16$ years (range, 46 to 76 years). The ring has 2 components: a circular ring used to undersize the circumference of the aortoventricular junction and 3-crown-like shape ring used for STJ remodeling. The circular ring was sutured into the left ventricular outflow tract in the aortic subvalvular position and the STJ ring was sutured from the outside of the aortic root just at the level of the STJ. The 3 vertical bands

$\mathrm{N}$ owadays, aortic valve repair (AVR) has evolved into an accepted treatment for patients with aortic regurgitation (AR). Recently, the results of AVR have dramatically improved, encouraging a wide interest and practice in aortic valve reconstruction [1-9]. This is due to lessons learned from mitral valve reconstructive operations when concomitant treatment of the leaflets diseases and annulus reshaping by a prosthetic ring emerged as optimal surgical choice with excellent long-term results. Moreover, annulus reshaping emerged as a fundamental step in mitral valve repair because it stabilizes the valve repair, improves the coaptation surface of the leaflets, and decreases closing stress, leading to better outcomes. So, in our opinion, the same concepts must be transferred to the AVR.

Understanding the mechanisms of aortic valve dysfunction and the etiology of lesions has greatly aided surgeons in techniques development. Several surgical techniques have been described to correct $A R$, according to the mechanisms of cusps dysfunction. Aortic cusp prolapse has been corrected by techniques attempting to shorten the free margin. The most commonly described

Accepted for publication Dec 29, 2010.

Address correspondence to Dr Fattouch, University of Palermo, Department of Cardiac Surgery, Via Liborio Giuffré 5, 90100 Palermo, Italy; e-mail: khalilfattouch@hotmail.com. of the STJ ring were fixed to the underlying circular ring to stabilize the continuity between the STJ and nadir of the aortic valve.

Results. No in-hospital death occurred. Two patients had residual trivial aortic valve regurgitation postoperatively, and 3 patients required treatment for residual aortic regurgitation (more than mild). Mean length of the coaptation surface was $10 \pm 2 \mathrm{~mm}$. The mean clinical follow-up (100\% complete) was $22 \pm 16$ months. All patients were free from cardiac and valve-related events, and no complications due to ring implantation occurred.

Conclusions. This ring reshapes the functional aortic annulus and stabilizes all components of the native aortic valve stent to improve long-term results of valve repair.

(Ann Thorac Surg 2011;91:1154-8)

(C) 2011 by The Society of Thoracic Surgeons

techniques are plication, triangular resection, free margin resuspension using a Gore-Tex suture (W. L. Gore and Associates, Flagstaff, AZ), and our approach, previously described, the chordae technique [10]. Aortic cusp tissue defect has been corrected by leaflets extension using a pericardial patch. Long-term results for these different operative techniques have been reported $[4,5$, 9-11].

On the other hand, few techniques have been described for aortic valve annuloplasty. Subcommissuralplasty was initially described by Duran and colleagues [12] and was widely used to reduce the circumference of the aortic annulus. Today, it represents the first surgical choice in aortic valve annuloplasty. In patients who underwent aortic cusp repair and valve-sparing reimplantation procedure, the aortic valve annulus was stabilized by a Dacron (DuPont, Wilmington, DE) graft. Lansac and colleagues [13], who performed valve-sparing remodeling technique, introduced the use of an external expansible subvalvular prosthetic aortic ring to stabilize the valve annulus. Recently, these authors introduced a new prosthetic ring (CoroNéo Inc, Montréal, Quebec,

Dr Fattouch discloses that he has a financial relationship with the Aortic Annuloplastic System. 
Canada) composed of 2 components for the treatment of both dilatation of the aortic valve annulus and of the sinotubular junction (STJ) [14].

We present a new approach to reshaping the functional aortic annulus and to stabilizing the continuity between the STJ and the nadir of the aortic valve (the aortoventricular junction). To achieve our goals, we designed a new prosthetic ring, and in the present study illustrate our surgical approach and describe our clinical results.

\section{Material and Methods}

\section{Patients}

Since February 2003, 196 patients with AR have undergone AVR in our institutions, among whom we used our aortic valve annuloplasty approach in 45 patients. Exclusion criteria were patients with dilatation of the aortic root or the ascending aorta exceeding $4.5 \mathrm{~cm}$, or both, and those with poor aortic wall quality who underwent aortic valve-sparing reimplantation or an ascending aorta replacement procedure.

Demographics and preoperative clinical characteristics of this cohort of patients are reported in Table 1. Patients were a mean age of $58 \pm 16$ years (range, 46 to 76 years). All patients underwent preoperative and postoperative transthoracic echocardiographic (TTE) examinations and intraoperative transesophageal echocardiographic controls. TTE was used preoperatively to measure the diameter of the aortic annulus, the Valsalva sinuses, the STJ, and the ascending aorta. The severity of the AR was

\section{Table 1. Patients Characteristics}

\begin{tabular}{lc}
\hline Variable & No. or Mean \pm SD \\
\hline Patients & 45 \\
Age, years & $58 \pm 16$ \\
Sex & 32 \\
$\quad$ Male & 13 \\
$\quad$ Female & $0.52 \pm 0.10$ \\
Mean LVEF & \\
NYHA grade & 19 \\
I and II & 26 \\
III and IV & \\
Grade of AR & 5 \\
III & 40 \\
IV & \\
Leaflets procedure & 25 \\
Plication & 10 \\
Free-edge reinforcement & 10 \\
Chordae technique & \\
Concomitant procedure & 2 \\
CABG & 1 \\
Mitral valve repair &
\end{tabular}

${ }^{\text {a }}$ Our approach to treat cusp prolapse [10].

$\mathrm{AR}=$ aortic regurgitation; $\quad \mathrm{CABG}=$ coronary artery bypass grafting; LVEF = left ventricular ejection fraction; NYHA = New York Heart Association functional class; $\quad \mathrm{SD}=$ standard deviation.

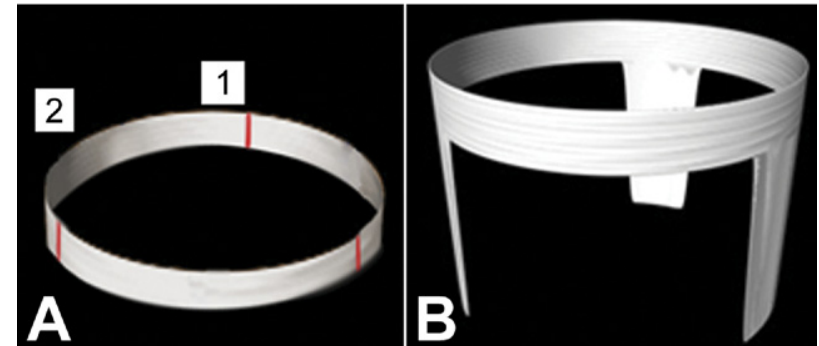

Fig 1. (A) Circular ring for subvalvular aortic annuloplasty: (1) the commissural zone and (2) the intercommissural zone. (B) The 3 crown-like shaped ring for the sinotubular junction annuloplasty.

evaluated semiquantitatively. The grade of AR was classified into mild (grade I), moderate (grade II), moderateto-severe (grade III), and severe (grade IV). Each patient signed an informed consent form. The study was approved by the Institutional Review Board of our University.

\section{Components of the Aortic Annuloplasty System}

The new ring is has 2 components. The first is a circular ring used to undersize the circumference of the aortic valve nadir (the aortoventricular junction; Fig 1A). The second is a 3 crown-like shaped ring used for the STJ remodeling (Fig 1B). The circular ring was constructed by the Simplici-T band (Medtronic, Minneapolis, MN). A Dacron graft (InterVascular Inc, Montvale, NJ) was scalloped to construct the ring for the STJ.

\section{Surgical Technique}

Our systematic approach to the aortic valve has been described in previous reports [10]. Cusp prolapse was treated by plication, free-edge reinforcement, or "the chordae technique." The plication technique was performed using a 6-0 Prolene suture (Ethicon Inc, Hamburg, Germany) placed in the central zone of the free margin of the cusp and extended perpendicularly from the free margin, about $5 \mathrm{~mm}$ through the belly of the leaflet to decrease cusp distension. The free edge reinforcement technique was performed using a CV-6 or CV-7 Gore-Tex suture passed in running fashion over and over, along the entire length of the free margin. Free margin shortening was obtained by applying tension on both Gore-Tex suture arms, which were locked at the level of the commissures when appropriate correction was reached.

All patients underwent aortic valve annuloplasty using our new approach. The circular ring was fixed into the left ventricular outflow tract just below the aortic valve nadir (the aortoventricular junction; Fig 2) and the 3 crown-like shaped ring was sutured to the STJ from the outside of the aortic root (Fig 3).

The circular ring was fixed into the left ventricular outflow tract in the subvalvular position. Ti-Cron 2-0 U stitches (Coviden, Mansfield, MA) were placed first on the prosthetic ring from inside to outside and subse- 


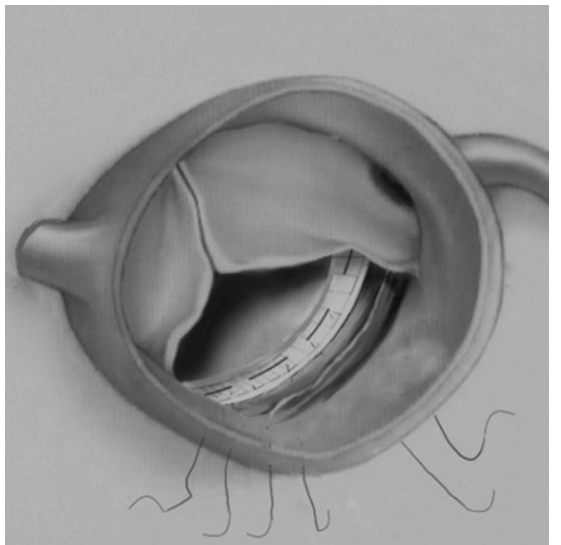

Fig 2. The circular ring is sutured into the left ventricular outflow tract just under the aortic valve cusps.

quently under the aortic leaflets like in the David procedure from inside to outside. Ti-Cron sutures were placed under the entire circumference of the aortic valve, except for the interleaflet triangles (Fig 4A). In this way, the interleaflet triangles were above the suture line and remained free to move during the cardiac cycle, reducing leaflets stress (Fig 4B). Under the coronaries ostia, the Ti-Cron $U$ stitches were placed through the aortic annulus from the ventricular side to the aortic side (as in valve replacement); in this way, we avoided the coronaries ostia mobilization that leads to easier and faster technique (Fig 4A).

The STJ ring was sutured from outside of the aortic root just at the level of the STJ using 4-0 Prolene sutures. The ring was sutured to the aortic wall using an overand-over running suture technique or by interrupted sutures. At the end of the procedure, the 3 vertical bands of the STJ ring were fixed to the underlying circular ring to stabilize the continuity between the STJ and the nadir of the aortic valve. The length of the 3 arms coming down was determined at the end of the procedure and was selected according to the distance between the STJ ring and the circular aortic ring. We took care to make the length of the arms not too short but slightly longer, to leave place for the root distension during cardiac cycle. The role of the 3 arms was to stabilize the distance between the aortic ring and the STJ ring and to avoid future upward displacement of the STJ in cases of ascending aorta or aortic root dilation.

\section{Sizing Method}

In all patients, the size (diameter) of the prosthetic circular ring was calculated according to the height of the leaflet measured from the Noduli of Arantius to the base of the cusp (Fig 5). The 3 leaflets were considered as the 3 triangles that cover the entire surface of a circle (the ring). Moreover, it must be left about $8 \mathrm{~mm}$ from the free margin of each cusp into the coaptation surface. We preferred to select the diameter of the ring according to the height of the smallest cusp because in this way we have the security of obtaining a good coaptation between all cusps.
The circular ring size must be calculated following the current formula Radius $(r)$ of the ring $=$ height of the cusp $-8 \mathrm{~mm}$.

The ring diameter used in our series was between 20 and $22 \mathrm{~mm}$. The surface of the ring was between 3.14 and $3.8 \mathrm{~cm}^{2}$ (diameter of the ring $=2 r$; surface of the ring $=$ $\left.\pi r^{2}\right)$.

The size of the STJ ring was calculated by the diameter of the native STJ plus 3 to $4 \mathrm{~mm}$. We used the Hegar sizer to measure exactly the diameter between the tips of the 3 commissures, taking the aortic valve in the closing position, and we added the thickness of the aortic wall. In our approach, the STJ ring is used to stabilize the STJ to avoid future dilatation. Accuracy must be taken to avoid the use of an undersized STJ ring because it leads to inward displacement of the commissures that may lead to cusps prolapse.

\section{Results}

Aortic valve annuloplasty with the new ring was successful in all patients. Cusp repair included plication in 25 patients, free edge reinforcement in 10, and "the chordae technique" in 10. Associated cardiac procedures included mitral valve repair in 1 patient and coronary artery bypass grafting in 2 patients. The mean cardiopulmonary bypass time was $118 \pm 35$ minutes (range, 85 to 177 minutes) and aortic cross-clamp time was $95 \pm 26 \mathrm{~min}$ utes (range, 68 to 155). Intraoperatively, 2 patients had residual trivial AR. A second pump run was needed in 3 patients and residual AR (more than mild) was eliminated; recurrent $A R$ was due to residual cups prolapse in the 3 patients.

No in-hospital death occurred. The mean postoperative hospital stay was $8 \pm 2$ days. At hospital discharge, the TTE control showed a trivial residual central AR in 2 patients. Mean length of the coaptation surface was $10 \pm$ $2 \mathrm{~mm}$. In all patients this approach was feasible, easy, and safe.

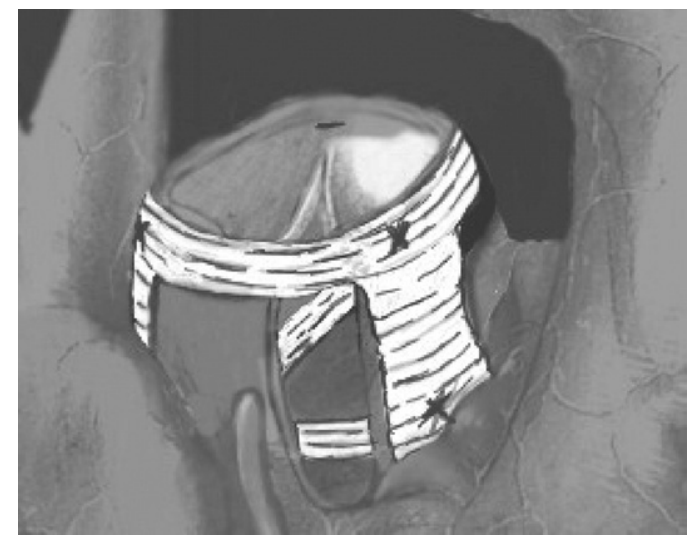

Fig 3. The sinotubular junction ring is sutured from outside the ascending aorta at the level of the sinotubular junction. The 3 vertical arms of the sinotubular junction ring were fixed to the underlying circular ring to stabilize the continuity between the 2 structures and to reshape the functional annulus. 


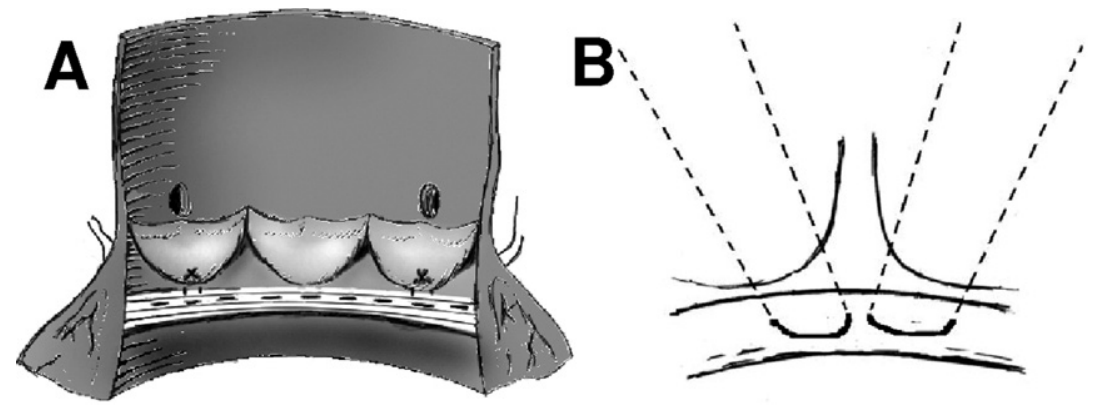

Fig 4. (A) The suture lines of the circular ring are above the nadir of the aortic valve. (B) The commissures and the interleaflets triangle are not included by the suture line. The 3 commissures are free to move during the cardiac cycle.

Follow-up was completed in all patients. The mean clinical follow-up time was $22 \pm 16$ months (range, 4 to 42 months). All patients were alive at follow-up and were in New York Heart Association functional class II or lower. The TTE control was performed in all patients and showed $4(9 \%)$ with trivial to mild AR. No aortic valve stenosis occurred, and no dehiscence of the ring components was observed. No patient needed reoperation and all were free from cardiac and valve-related events.

\section{Comment}

In the last decade, due to a better understanding of the surgical anatomy of the aortic valve, underlying dysfunction mechanisms, functional classification of $\mathrm{AR}$, and improvement in operative techniques, AVR is now considered as a good surgical approach for patients with aortic valve insufficiency. Several authors showed an improvement of long-term surgical results for the aortic cusps repair [1-10].

The aortic valve annuloplasty was often performed by subcommissural plasty using Ti-Cron 2-0 suture reinforced with Teflon (DuPont) or pericardial pledgets placed at the base of the interleaflets triangle. The circumference of the aortic valve was reduced, and the surface of leaflets coaptation improved. In our opinion, the controversies about this type of annuloplasty emerged from several considerations:

First, subcommissural annuloplasty is focused only on

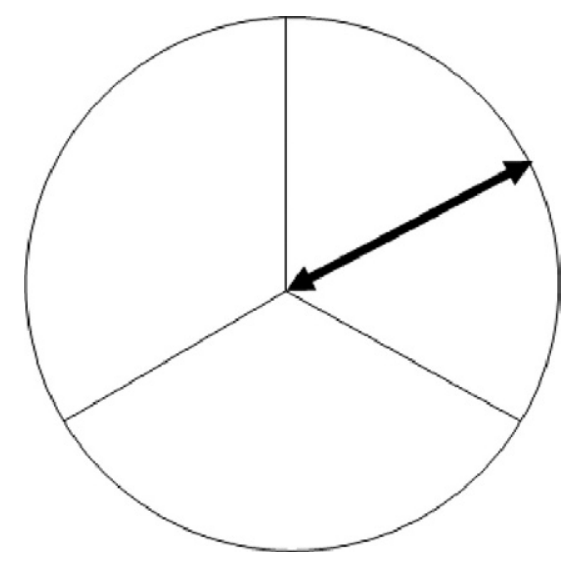

Fig 5. The arrow illustrates the high of the cusp measured to calculate the circular ring diameter. treating one component of the aortic annulus (the nadir or aortoventricular junction), leaving the second component (the STJ) untreated. We already know that the aortic valve annulus does not have a circular bidimensional shape; it is a complex tridimensional structure composed by the nadir of the aortic leaflets, by the commissures, and by the STJ. The STJ joins together the apex of the 3 commissures and its dilatation lead to outward displacement of the commissures causing AR. Conceptually, this is important because while doing an aortic annuloplasty we must be concerned with all components of the native annulus structure (the functional aortic annulus) and not only the aortoventricular junction. So, any type of aortic valve prosthetic ring must concern all components of the functional aortic annulus.

Second, using the subcommisural plasty technique, we are not able to decide the exact amount of the annulus diameter reduction. We just include and fix the commissures by the sutures, meanwhile, their movements are fundamental to preserve valve motion and reduce the stress on the aortic leaflets. Moreover, some authors found the failure of the subcommissural plasty specifically in patients with AR and a dilated left ventricle [11].

Actually, the Lansac ring [14] appears helpful, but more clinical results are needed to clarify the long-term efficacy. The aortic annuloplasty technique described by these authors consists in the application of the prosthetic ring at the level of the aortoventricular junction from outside the aortic root in a subvalvular position. This procedure may have some technical difficulty and fail to reach the annulus-reshaping concept. This technique needs mobilization of the coronaries ostia that add risk to the standard procedure. On the other hand, the aortic annulus plan is limited from the outside by anatomic structures, such as the right ventricular outflow tract and the pulmonary artery that leads to a difficulty in application of a prosthetic ring just in the subvalvular position. Sometimes, it may result in shrinking the annulus from outside instead of reshaping it.

The advantage of our approach is given by the easy technique in suturing the ring in subvalvular position. The suture line is placed under the aortic leaflets into the left ventricular outflow tract from inside to outside. This leads to an accurate suturing technique with a correct geometric undersizing of the aortic orifice without any interaction with the cusps motion. The commissures and the interleaflets triangle are above the suture line and are 
free to move during the cardiac cycle, reducing the stress on the leaflets. Moreover, there are no anatomic limitations to the ring insertion within the left ventricular outflow tract, and the coronaries ostia are still untouched.

The STJ ring suturing technique is very easy and was performed by a running suture using 4-0 Prolene or by interrupted sutures. At the end of the procedure, the 3 bands of the ring must be sutured and fixed to the underlying circular ring. In this manner we stabilize the continuity between the STJ and the nadir of the aortic valve and we reshape completely the functional aortic annulus. The sizing technique of the ring is easy and was efficient in all cases.

We performed our approach for aortic annuloplasty in 45 patients in combination with cusps treatment. When the procedure was completed, the leaflets coaptation was high, and valve competency was easily determined by transesophageal echocardiographic examination. No restrictive leaflet motion or aortic valve stenosis were observed intraoperatively or at follow-up. Trivial to mild AR occurred in only 4 patients $(9 \%)$. Although valve competency and leaflets motion are satisfactory in the immediate and medium-term, further experience and long-term follow-up are need to evaluate the durability and efficacy of this technique. In our opinion, this technique is easy, safe, and reproducible.

The authors thank Dr Gaetano Vitale and Dr Sebastiano Castrovinci for their assistance in photo editing.

\section{References}

1. El Khoury G, Vanoverschelde JL, Glineur D, et al. Repair of aortic valve prolapse: experience with 44 patients. Eur J Cardiothorac Surg 2004;26:628-33.
2. Carr JA, Savage EB. Aortic valve repair for aortic insufficiency in adults: a contemporary review and comparison with replacement techniques. Eur J Cardiothorac Surg 2004; 25:6-15.

3. Minakata K, Schaff VH, Zehr JK, et al. Is repair of aortic valve regurgitation a safe alternative to valve replacement? J Thorac Cardiovasc Surg 2004;127:645-53.

4. Casselman FP, Gillinov AM, Akhrass R, Kasirajan V, Blackstone EH, Cosgrove DM. Intermediate-term durability of bicuspid aortic valve repair for prolapsing leaflet. Eur J Cardiothorac Surg 1999;15:302-8.

5. Ahn H, Kim K-H, Kim YJ. Midterm result of leaflet extension technique in aortic regurgitation. Eur J Cardiothorac Surg 2002;21:465-69.

6. Talwar S, Saikrishna C, Saxena A, Kumar AS. Aortic valve repair for rheumatic aortic valve disease. Ann Thorac Surg 2005;79:1921-5.

7. El Khoury G, Vanoverschelde JL, Glineur D, et al. Repair of bicuspid aortic valves in patients with aortic regurgitation. Circulation 2006;114;(suppl I):I-610-6.

8. Schafers HJ, Aicher D, Langer F, Lausberg HF. Preservation of the bicuspid aortic valve. Ann Thorac Surg 2007;83: S740-5.

9. Langer F, Aicher D, Kissinger A, et al. Aortic valve repair using a differentiated surgical strategy. Circulation 2004; 110(suppl II):II-67-73.

10. Fattouch K, Sampognaro R, Bianco G, et al. Implantation of Gore-Tex chordae on aortic valve leaflet to treat prolapse using "the chordae technique": surgical aspects and clinical results. Ann Thorac Surg 2008;85:2019-25.

11. De Kerchove L, Boodhwani M, Glineur D, et al. Cusp prolapse repair in trileaflet aortic valves: free margin plication and free margin resuspension techniques. Ann Thorac Surg 2009;88:455-61.

12. Duran CM, Pomar JL, Caro M. Changing concepts in the surgical treatment of acquired valvular diseases. Annuloplasties. J Cardiovascular Surg (Torino) 1973;Spec No. 387-9.

13. Lansac E, Di Centa I, Bonnet N, et al. Aortic prosthetic ring annuloplasty: a useful adjunct to a standardized aortic valvesparing procedure? Eur J Cardiothorac Surg 2006;29:537-44.

14. Lansac E, Di Centa I, Raoux F, et al. An expansible aortic ring for a physiological approach to conservative aortic valve surgery. J Thorac Cardiovasc Surg 2009;138:718-24. 